\title{
Formação de grupos em ciências da linguagem: o caso do GEL
}

DOI: http://dx.doi.org/10.21165/el.v49i1.2812

\section{Cristina Altman'}

\author{
Por ocasião dos 50 anos de criação do \\ Grupo de Estudos Linguísticosdo Estado de São Paulo² \\ (On the occasion of the $50^{\text {th }}$ anniversary of the \\ Group in Linguistics Studies of the State of São Paulo)
}

\section{Resumo}

O pequeno grupo de jovens professores universitários - Ataliba Teixeira de Castilho, USP e UNICAMP (então, de Marília); Cidmar Teodoro Pais (1940-2009), USP; Francisco da Silva Borba, Araraquara; Ignácio Assis da Silva, São José do Rio Preto (?-?) e João de Almeida, Assis (1929-2019) - que se reuniu em Araraquara, em 1969, no primeiro seminário do GEL, nunca poderia imaginar que a iniciativa assumisse a extensão que vemos hoje. Estimulados pelo mestre Isaac Nicolau Salum, USP (1913-1993), o grupo pretendia a criação de um espaço que propiciasse a veiculação e, principalmente, a convergência das "novas" ideias em matéria de ciência da linguagem, que então mal começavam a delinear-se no contexto brasileiro. Desde então, o GEL tem exercido, ininterruptamente, essa função. O objetivo do texto é revisitar a história da formação do GEL, que se confunde com a história das mudanças relativas à concepção dos problemas e das formas de tratamento do objeto linguagem e com a história da institucionalização e profissionalização da Linguística no Brasil.

Palavras-chave: GEL; linguistas brasileiros; historiografia linguística brasileira.

\footnotetext{
1 Universidade de São Paulo (USP), São Paulo, São Paulo, Brasil; altman@usp.br; http://orcid.org/0000-0002-5121-4282

20 presente texto é a versão escrita da palestra proferida na Sessão de Abertura do $67^{\circ}$ Seminário do GEL, realizado em São José do Rio Preto, entre 16 e 19 de julho de 2019. Agradeço mais uma vez a calorosa acolhida dos colegas da Diretoria, Luciani Tenani, Claudia Zavaglia, Suzi Cavalari, Edson Rosa de Souza, e a delicadeza com que nos homenagearam, a todos nós, coparticipantes da história do GEL. A todos, meu reconhecido afeto.
} 


\title{
Group formation in language sciences: the case of GEL
}

\begin{abstract}
The small group of young scholars — Ataliba Teixeira de Castilho, USP and UNICAMP (from Marilia, at the time); Cidmar Teodoro Pais (1940-2009), USP; Francisco da Silva Borba, Araraquara; Ignácio Assis da Silva, São José do Rio Preto (?-?) and João de Almeida, Assis (1929-2019) — who met in Araraquara, in 1969, inaugurating GEL's seminars, could never imagine that their initiative would have the relevance we see today. Encouraged by their master, Isaac Nicolau Salum, USP (1913-1993), the group intended to create a space where the 'new' ideas in language sciences subject, barely known within Brazilian context, would converge and circulate. Since then, GEL has uninterruptedly played this role. The purpose of this text is to revisit GEL's formation history, which blends with the history of changes in the conception of problems and the forms of treatment of the object-language and with the history of the institutionalization and the professionalization of Linguistics in Brazil.
\end{abstract}

Keywords: GEL; Brazilian linguists; Brazilian Linguistic Historiography.

\section{Introdução}

Em textos anteriores (ALTMAN, 1994a, 1994b), procurei demonstrar que a geração de linguistas brasileiros que atingiu a maturidade acadêmica em meados do século XX, i.e., que começou a se profissionalizar por volta dos anos 1960, é, do ponto de vista da formação de uma memória das ciências da linguagem no Brasil, especial. Com efeito, esta geração foi a primeira a testemunhar a expansão das universidades no país, a promover a institucionalização da disciplina Linguística em todas as faculdades de Letras e a participar da criação, publicação e circulação da produção monográfica e periódica que nos autoriza a falar hoje de uma tradição brasileira de pesquisa linguística. Fundadora de "novos" valores intelectuais e institucionais, essa geração, que foi também a que inventou o GEL, contribuiu para que as expectativas (e as coerções) sobre o trabalho acadêmico mudassem de eixo em relação às gerações anteriores.

Dentro desse movimento, o pequeno grupo de jovens professores universitários - Ataliba Teixeira de Castilho (então, de Marília), Cidmar Teodoro Pais (USP), Francisco da Silva Borba (Araraquara), Ignácio Assis da Silva (São José do Rio Preto) e João de Almeida (Assis) - que se reuniu em Araraquara no primeiro seminário do GEL, em 1969, juntamente com alguns alunos, nunca poderia imaginar que a iniciativa assumisse a dimensão que vemos hoje. Estimulados pelo mestre, Isaac Nicolau Salum (1913-1993), também da Universidade de São Paulo, esse pequeno grupo pretendia a criação de um espaço que propiciasse a veiculação e, principalmente, a convergência das novas ideias em matéria de ciência da linguagem que então começavam a circular no país. 
No que diz respeito ao contexto intelectual imediato a esse grupo, o clima geral dos anos 1960 era de insatisfação. Insatisfação, em primeiro lugar, com o caráter profissionalizante que assumiram as Faculdades de Filosofia, em detrimento das atividades de pesquisa. Como se sabe, as Faculdades de Filosofia de São Paulo (1934) e do Rio de Janeiro (1935) deveriam constituir, em princípio, o ambiente propício para o desenvolvimento de pesquisas na área, mas, ao contrário das expectativas, o grau superior acabou por privilegiar a formação do professor. Não que não tivesse havido avanços em pesquisa desde então, tanto do ponto de vista intelectual quanto institucional: a produção gramatical de orientação histórica na primeira metade do século foi volumosa e os projetos de mapeamento dialetal das variantes do Português do Brasil ensaiaram voos mais científicos com a recepção da Geografia Linguística (cf. ALTMAN, 2018). Tanto é que datam dos anos 1950 a criação de um Centro de Estudos Dialetológicos no Museu Nacional, Rio de Janeiro, em 1953; a fundação de um periódico em moldes internacionais, a Revista Brasileira de Filologia (1955-1961, 11 números, não corrente), que Serafım da Silva Neto (1927-1960) dirigiu até sua morte prematura; e a criação de um Centro de Estudos Linguísticos, também no Museu Nacional, em 1958, dirigido por Mattoso Câmara Jr. (1904-1970).

Em segundo lugar, a questão que também provocava insatisfação em boa parte da comunidade acadêmica relevante dizia respeito não apenas à implantação descontínua e tardia da disciplina Linguística nos currículos de Letras, mas, principalmente, à maneira como foi finalmente feita, em 1962: por uma Resolução Federal. Sem qualquer preparo prévio, os scholars brasileiros dos anos 1960 tiveram que assumir, da noite para o dia, o ensino da disciplina em todas as Faculdades de Letras do país - noventa, ao todo - e, ao mesmo tempo, implementar uma política de ensino e pesquisa tal que produzisse, no prazo mais curto possível, um contingente minimamente especializado, capaz de, sobretudo (a ênfase ainda é a formação de professores) ministrar a disciplina, em nível de $3^{\circ}$ grau.

A tudo isso, some-se, entre outros fatores, o violento processo de crescimento e agravamento dos desajustes econômicos e sociais por que passava a sociedade brasileira do período - aí inclusa a expansão desordenada das redes de ensino de $1^{\circ}, 2^{\circ}$ e $3^{\circ}$ graus - e o impulso reformista que caracterizou os debates universitários da primeira metade da década de sessenta ${ }^{3}$. Debatiam-se, entre outros temas, a autonomia universitária, a democratização da carreira docente, a democratização do acesso ao ensino superior, a implantação de cursos de pós-graduação, os currículos e a atividade político-partidária nas Universidades (CASTILHO, 1963).

O clima contestatório do período precipitou mudanças na estrutura universitária (V. PROTA, 1987; ADUSP, 1979; DURHAM, 1986) e propiciou o surgimento do que Murray

3 Veja-se, a este respeito, Castilho (1963), Salum (1972/1973), Fiorin (1986/1987) e Naro (1976). 
(1994) denominou lideranças intelectuais e lideranças organizacionais ${ }^{4}$. No final da década de sessenta se concentrou, principalmente em São Paulo, um conjunto de fatores de ordem intelectual e social que permitiu a implantação de uma disciplina considerada progressista, a Linguística ${ }^{5}$. Em contraste, a Filologia, neste contexto, era associada ao establishment conservador que urgia combater. A "nova" disciplina Linguística permitiria, na visão das lideranças da época, que se chegasse mais perto da efervescente realidade brasileira, entre outras razões, porque autorizava trazer o popular, o falado, o contemporâneo, o ordinário para dentro da Universidade. Estava preparado o terreno de onde emergiria o grupo de professores pesquisadores que começaram, a partir de então, a se reconhecer linguistas. Havia, em suma, um terreno favorável à recepção de novas ideias, e a disciplina Linguística se apresentou como um caminho promissor a ser seguido (ALTMAN, 1994b).

\section{A emergência do GEL}

Embora o programa de uma disciplina Linguística nos anos sessenta fosse ainda para muitos uma vaga promessa, a geração que fundou o GEL parecia convicta de que duas estratégias precisavam ser adotadas para modernizar os estudos linguísticos que se praticavam no país: a primeira consistia em revisitar "velhos" problemas linguísticos com o rigor científico exigido pelas novas metodologias de descrição linguística; a segunda, em promover novos tópicos de estudo no ensino universitário, calcados na leitura de autores europeus e americanos, até então pouco estudados pela comunidade universitária paulista. A revisão dessa "nova" literatura uniformizaria a informação entre o corpo docente e discente das faculdades paulistas e promoveria, era de se esperar, o surgimento de temas de pesquisa mais consentâneos com a realidade em transformação.

\subsection{Algumas questões de método}

O trabalho com dados de língua oral, o rigor descritivo, e os modelos estruturalistas passavam, pois, à ordem do dia. Tratava-se de descrever a língua portuguesa viva, contemporânea, não mais o estudo da România velha, nos termos de Castilho, mas, da România nova. Para isso, crescia o interesse pelo estabelecimento de normas de transcrição fonética, de procedimentos para a identificação e classificação de fonemas,

\footnotetext{
4 Ao contrário do que certa literatura historiográfica tende a considerar, a liderança, tanto a organizacional quanto a intelectual, não corresponde obrigatoriamente a um indivíduo que se destaca, ao contrário, lideranças são funções do conhecimento científico que podem ser exercidas por um ou mais pesquisadores, um funcionário burocrático ou até um grupo (MURRAY, 1994).

5 Em 1969, aconteciam na USP o II Instituto Brasileiro de Linguística (III Interamericano PILEI) e - Il Congresso da ALFAL, o que significou uma concentração excepcional em São Paulo de pesquisadores de vários pontos do país interessados em marcar oficialmente a existência de uma Linguística Brasileira. Neste ano também é criada a Associação Brasileira de Linguística (então ABL) e se realiza o / Seminário do GEL, em Araraquara.
} 
de morfemas, etc. O grupo chamou para si, com sucesso, a função de mostrar à então incipiente comunidade dos linguistas locais o que havia de novo em matéria de análise linguística. Observe-se a programação da primeira reunião do GEL, em 1969, em Araraquara e a ênfase dada a procedimentos para o tratamento dos dados linguísticos:

Quadro 1. Programação da primeira reunião do GEL, em 1969, Araraquara

\begin{tabular}{|l|l|l|}
\hline Professor/ Pesquisador & Instituição & Tema do trabalho apresentado \\
\hline Isaac Nicolau Salum & USP & Métodos de investigação histórica \\
\hline Cidmar Teodoro Pais & USP & Tratamento estatístico \\
\hline Francisco S. Borba & Araraquara & Seleção e tratamento do corpus \\
\hline A. de Castilho e João de Almeida & Marília e Assis & Projeto NURC \\
\hline Ignácio Assis da Silva & S. J. do Rio Preto & Análise estratificacional \\
\hline
\end{tabular}

Fonte: GEL

Os temas indicam as relações assimétricas, e nem sempre pacíficas, aliás (cf. Alfa 11, 1967), entre uma linguística de orientação histórica, diacrônica, e uma linguística de orientação sincrônica. A tensão entre essas duas orientações, igualmente no foco da descontinuidade entre a filologia e a linguística dos anos sessenta, aos poucos concretizaria a ruptura entre as duas práticas: as análises filológicas veriam reduzidos, cada vez mais, seus espaços de produção e divulgação e as análises linguísticas, fragmentadas em múltiplas metodologias, atrairiam para si cada vez mais atenção. Recupero mais uma vez um trecho de correspondência inédita, de 1973, entre dois ativos participantes do GEL, Borba e Castilho, que bem ilustra o clima intelectual do momento6.

[...] você sabe como sou reacionário em matéria de Linguística. Imagine que só comecei a levar a sério o Estruturalismo depois que o Transformacionismo o considerasse meio quadrado e algo superado. Isto bastou para que logo houvesse uma identificação entre mim e o Estruturalismo, que eu verdadeiramente não suportava em meus primeiros tempos de magistério superior. Isto implica, no caso do GEL, numa enorme restrição do seu adjetivo "moderno": o moderno para mim ainda exclui o Transformacionismo e outros ismos. Não que os ignore completamente, mas é uma questão de aversão ao prato do dia. [...] (CEDAE, Fundo Ataliba T. de Castilho, Doc. 1, manuscrito inédito).

6 Agradeço uma vez mais à aluna Susan Klein Franchetti (DL-USP) que me cedeu cópia do texto original, arquivado no CEDAE-IEL, UNICAMP, e aos responsáveis pelo Fundo Ataliba de Castilho, pela permissão de reproduzir parcialmente o trecho da carta. 
As eventuais tentativas de acomodação entre as práticas filológica e linguística stricto sensu, sempre pontuais, buscavam adaptar as metodologias extraídas desses novos referenciais a temas já tratados pela tradição filológica, como a diversificação dialetal, por exemplo. Os temas em evidência na segunda reunião do GEL, ainda em 1969, em Marília, ilustram essas tentativas de integração, ao menos o que diz respeito à Dialetologia.

Quadro 2. Programação da segunda reunião do GEL, em 1969, em Marília

\begin{tabular}{|l|l|l|}
\hline Professor/ Pesquisador & Instituição & Tema do trabalho apresentado \\
\hline Ada Natal Rodrigues & USP & Dialetologia brasileira \\
\hline Erasmo d'Almeida Magalhães & USP & Linguística indígena \\
\hline Maria Tereza C. Biderman & Araraquara & Conceito de palavra \\
\hline Brian Head & Campinas & Guia para a pesquisa fonológica \\
\hline
\end{tabular}

Fonte: GEL

Com efeito, Ada Natal Rodrigues (fl. 1970), em sua tese de Doutorado, orientada por Salum, aplicou o aparato descritivo do Programa Gerativista (então conhecido como Gramática Gerativo-Transformacional) à primeira parte do seu estudo sobre 0 dialeto caipira na região de Piracicaba (v. RODRIGUES, 1974), retomando a tese de Amadeu Amaral (1875-1929) cinquenta anos depois. Não sem antes alfinetar o que provavelmente percebia como uma versão exótica e deslocada das propostas "modernas" para o estudo da variação linguística no Brasil. Para Ada Natal, a modernização da pesquisa linguística não era uma questão temática, mas sim, metodológica. Observe-se o seguinte trecho extraído da introdução ao livro que publicou a partir da sua tese:

O entusiasmo pelos estudos linguísticos no Brasil tem conduzido as investigações para o terreno puramente teórico, para a análise de textos escritos ou textos elocucionais cultos, isto é, urbanos, culminando com uma pesquisa de caráter internacional, [...]. Poucos se têm dedicado aos dialetos não-cultos, presumindo alguns ser este um campo ultrapassado na linguística contemporânea, confundindo-se, evidentemente, tema e método. (RODRIGUES, 1974, p. 21, grifos da autora).

O alvo principal da ironia de Ada Natal naquele momento é, como sabido, o Projeto $N U R C^{7}$ que agregou, ao final dos anos sessenta, pesquisadores de várias universidades

7 O Projeto NURC (Norma Urbana Culta) data de 1968, "[...] como desdobramento e extensão do Proyecto de Estudio Coordinado de la Norma Lingüística Culta de las Principales Cidades de 
brasileiras (São Paulo, Rio de Janeiro, Belo Horizonte, Recife, Porto Alegre) com o objetivo definido de ultrapassar a dialetologia rural, voltada para o registro de variantes regionais ameaçadas de extinção, à dialetologia vertical, urbana, voltada para o registro de variantes sociais. Não por acaso, a partir da década de sessenta, o Brasil deixará de ser um país predominantemente rural e viverá o boom da urbanização ${ }^{8}$. Paralelamente à bibliografia estruturalista que adentrava no cenário brasileiro, via Currículos Mínimos Federais das Faculdades de Letras, autores como Labov, Sankoff, Gumperz, Hymes, Weinreich, Bernstein eram chamados a constar, como corpo teórico autorizado, da bibliografia pertinente à descrição do padrão brasileiro.

\subsection{Algumas questões de ensino}

O projeto que reuniu os pesquisadores dedicados ao estudo das linguagens e das línguas no Brasil foi, como detalhado em Altman (1994b), um projeto essencialmente prático, i.e., não foi uma teoria, ou mesmo um conjunto de teorias afıns que reuniu os interessados em desenvolver a pesquisa linguística no Brasil. O que os uniu, enquanto grupo de especialidade, foi, principalmente, um projeto pedagógico. Coube a essa geração informar sobre e ensinar como os alunos de Letras deveriam fazer linguística. A segunda proposta do grupo que se aglutinava em torno do GEL se deu exatamente nesta direção. Para isso visavam:

a) a uma programação unificada de Linguística para os cursos de Letras (proposta do VI Seminário, Franca, em 1971);

b) a uma coletânea de textos fundadores da disciplina Linguística, o que também uniformizaria a informação entre os alunos. No mesmo seminário de Franca foi aprovada a proposta e eleita uma comissão para executar o projeto, de que outros, de certa maneira, dependeriam. Assim, no VII Seminário (Bauru, em 1972) foi aprovada a edição de uma coletânea de textos de Linguística e de Língua Portuguesa.

A proposta inicial dessa coletânea previa a publicação de 4 volumes (VIII Seminário, Araçatuba, 1972): um primeiro volume de Noções básicas; um segundo dedicado à Fonética e Fonologia; um terceiro à Morfossintaxe; e um quarto à Lexicologia e Semântica.

Iberoamérica y de la Península Ibérica, de autoria do Professor Juan M. Lope Blanch do Colégio de México." (PRETI, 1981, p. 290).

8 "É de nossos dias a formação das grandes comunidades urbanas, agremiando muitas vezes uma notável parcela da população nacional. Tem sido lembrado neste particular que 1/7 dos mexicanos e 1/3 dos argentinos residem em suas respectivas capitais. No caso brasileiro, particularizando o do Estado de São Paulo, quase 1/2 dos habitantes vivem na capital, São Paulo. Tais centros, auxiliados pelos modernos meios de comunicação, transformam-se em centros irradiadores de padrão linguístico, o qual importa descrever." (CASTILHO, 1972/1973, p. 124). 
Cada participante do projeto selecionaria um texto do assunto que lhe coubera; traduziria este texto; redigiria notas explicativas, elaboraria um questionário de fixação e ainda acrescentaria um sumário de leituras subsidiárias recomendadas. O fato de cada participante declarar, explicitamente, que abria mão de qualquer direito autoral a favor do GEL mostra o forte grau de coesão em torno dos compromissos do grupo (cf. nota 9).

Descritivamente, o exame dos textos que teriam constituído o Volume I aponta para uma forte recepção de autores da chamada Linguística estrutural funcionalista, que chegava até nós através das publicações francesas, em intersecção com autores da chamada Semiologia estrutural: Mattoso Câmara, Saussure, Malmberg, Martinet, Coseriu, Benveniste, Barthes; Trubetzkoy, Jakobson, Mounin faziam parte central da coletânea. Mas não só, dela também constavam textos de Bloomfield, Ullman, Lyons e Ruwet ${ }^{9} \mathrm{e}$ alguns textos da tradição portuguesa. O projeto de elaboração de uma coletânea (crítica) de textos de Linguística propiciaria, sem dúvida alguma, a realização das principais metas do grupo: garantir uma programação unificada de Linguística para todas as Faculdades de Letras, o que possibilitaria, por sua vez, o intercâmbio de pesquisadores em torno de um programa de descrição da língua (portuguesa) contemporânea.

A rápida obsolescência das teorias e modelos em competição na Linguística Geral daquele momento, entretanto, comprometeria a execução desse projeto no nascedouro. O grupo do GEL logo se deu conta de que, para além da literatura estruturalista que lhe parecia a mais avançada, outros modelos concorrentes, mais "modernos", despontavam no horizonte. A coletânea do GEL, antes mesmo de ir ao prelo, foi percebida pelos organizadores como anacrônica e o projeto foi abortado ${ }^{10}$.

\section{0 trabalho em grupo}

É pertinente enfatizar que o GEL, desde sua fundação, nunca apresentou uma retórica de ruptura com os pesquisadores ligados às tradições de pesquisa que o antecederam, seja nos campos da Filologia e da Dialetologia tradicionais, seja nas múltiplas orientações teóricas que pouco a pouco pulverizaram o campo da teoria linguística e das suas

9 Ao resgatar os nomes dos tradutores do Vol. I da coletânea, resgatamos também parte dos nomes daqueles jovens profissionais que se aglutinavam, enquanto grupo de especialidade, em torno do projeto do GEL. Foram eles: Rafael E. Hoyos-Andrade, Erasmo D'Almeida Magalhães, Maria Lúcia Pinheiro Sampaio, Alceu Dias Lima, Jesus Antonio Durigan, Salvatore D’ Onofrio, Carlos de Assis Pereira, Vandersí Santana, Pedro Caruso, Ignácio Assis da Silva, Maria Ângela Abud, Telmo Correa Arrais, Zilda Zapparoli, Idméia Semeghini, José de Almeida Prado e Assuer Quadri Prestes.

10 Ataliba de Castilho, em comentário à apresentação deste texto, confirma ter sido essa a principal razão do abandono do projeto da coletânea de textos. Segundo ele, as notícias de que essa literatura estava ultrapassada em outros círculos vinham de Carlos Franchi (1932-2001). 
subdisciplinas, seja no campo das literaturas vernáculas ou estrangeiras. Ao contrário, o GEL sempre se declarou, desde o início, aberto a comunicações de professores de língua portuguesa, linguística, linguística românica, língua latina, línguas estrangeiras, línguas indígenas brasileiras e respectivas literaturas ${ }^{11}$.

Assim é que, nas reuniões seguintes, para além da frustrada coletânea, outros projetos coletivos foram surgindo e novas comissões foram sendo montadas, como o projeto de elaboração do Atlas Linguístico de São Paulo (X Seminário, Avaré, 1973); o projeto de implantação de uma Linguística Aplicada à L2 (XI Seminário, Tupã, 1974), com a contribuição de professores de línguas estrangeiras e de didática de línguas; como a comissão de avaliação das contribuições do Estruturalismo e da Gramática Transformacional; como a comissão de análise do material do Projeto NURC.

Nesse sentido, do ponto de vista da institucionalização das ciências da linguagem no Brasil, o GEL assumiu, naqueles anos conturbados da vida brasileira, em que até os Centros Acadêmicos não tinham permissão para existir, um valor simbólico de defesa à liberdade de associação e de discussão intelectual que é preciso manter vivo na lembrança das novas gerações. Não se pode esquecer de que o GEL emergiu precariamente, enquanto agrupamento profissional, no atual campus da Universidade de São Paulo, logo após o fechamento do prédio da Faculdade de Filosofia na Rua Maria Antônia e dos acontecimentos que nele culminaram. Tratava-se, naquele momento, não só do resgate de um espaço físico, mas também da reafirmação de um conjunto de valores acadêmicos que necessitavam, segundo a geração que criou o GEL, ser reinterpretados em conformidade com o conturbado contexto brasileiro da década de 1960. O GEL exerceu, pois, em primeiro lugar, uma importante função congraçadora para a dispersa comunidade de profissionais interessados em questões linguísticas, e, ao mesmo tempo, divulgadora do novo ideário linguístico que começava a adentrar no país.

Do ponto de vista interno, as motivações do GEL também se revelaram generosas. Tratavase de (re)definir, em conjunto, as novas linhas de pesquisa a seguir nos diversos cursos de Letras que pipocavam pelo estado, e de, ao mesmo tempo, divulgar as informações sobre as teorias e práticas de análise linguísticas advindas de outras tradições que não unicamente a da Filologia Portuguesa. Neste sentido, é importante enfatizar que o GEL emergiu no contexto científico brasileiro como uma primeira tentativa de solução adaptada às especificidades regionais, resultado da reflexão, sempre conjunta, sobre problemas relativos ao ensino e à pesquisa linguística conformes à realidade do país: temática subjacente até hoje aos seus seminários anuais, e que the garante um perfil original em relação às demais sociedades regionais, que surgiram depois dele, mas que lhe são coirmãs.

11 Ao contrário da ABRALIN, por exemplo, que tinha critérios de inclusão/exclusão de associados. 


\section{A título de conclusão}

A relevância dos seminários, projetos coletivos, e publicações do GEL para o cenário científico brasileiro pode ser apreciada hoje por três grandes conjuntos de parâmetros: historicidade, periodicidade e grau de abrangência (ALTMAN, 2002, 2003).

De fato, desde 1969 o GEL tem apresentado com rara regularidade na periodicidade, considerados os padrões latino-americanos, tanto os seminários, quanto as publicações que os registraram - Estudos Linguísticos. Anais de Seminários do GEL, mantidos ininterruptamente, desde o número I, de 1978, e a Revista do GEL, ininterrupta desde o número Piloto, em Homenagem a Carlos Franchi, de 2002. Tal regularidade significa que os textos proferidos nas suas diferentes sessões, bem como as publicações que lhes correspondem, assim como as contribuições para a Revista, compõem hoje respeitável material documental sobre a evolução de boa parte da pesquisa linguística brasileira e constituem, dessa maneira, uma das fontes mais representativas dos problemas linguísticos considerados relevantes pela comunidade científica da especialidade. Inegavelmente, a história e relevância do GEL se confundem em grande parte com a história das mudanças relativas à concepção dos problemas e das formas de tratamento e ensino do objeto linguagem/línguas naturais, e com a história da institucionalização e profissionalização da linguística brasileira.

É preciso acrescentar ainda que o GEL, ao longo do tempo, assumiu a envergadura de uma sociedade suprarregional, procurada principalmente por pesquisadores das regiões sudeste, sul e centro-oeste como canal principal de divulgação da sua produção científica e de busca de novos contatos e/ou de público crítico para discussão dos seus trabalhos. O gigantismo do GEL está correlacionado a um aumento expressivo da participação de alunos da pós-graduação (o que, por sua vez, sugere um aumento paralelamente expressivo de cursos de pós-graduação por todo o Estado), que comparece em atividades coordenadas e/ou em grupos liderados por seus orientadores. Este tipo de participante parece ser sazonal, i.e., não é sócio efetivo, embora se inscreva oficialmente nos eventos de que participa e seu comparecimento esteja mais condicionado à presença de colegas e/ou de seu orientador, do que a algum comprometimento com a Associação. Seja como for, tal característica confere hoje ao GEL o estatuto do mais democrático fórum de debates para pesquisadores da linguagem: iniciantes, veteranos, alunos de graduação, pós-graduação, professores e orientadores convivem, lado a lado, nas mesas montadas pelo GEL. Todos se sentem duplamente motivados ao verem suas propostas de trabalho igualmente discutidas, e compreendidas, seja por quem as aplica, seja por quem as critica.

Precisar até que ponto essa função-satélite que o GEL parece exercer em relação a instituições menores enfraquecerá a vitalidade de outras sociedades regionais é ainda uma incógnita. A criação do GELCO (Grupo de Estudos Linguísticos do Centro-Oeste), do 
GELES (Grupo de Estudos Linguísticos do Espírito Santo), ao lado das já existentes ASSEL, CELSUL e GELNE indica que não.

Em suma, o GEL contribuiu para a democratização do acesso à pesquisa linguística e para a diluição das funções administrativas e científicas das antigas e inacessíveis cátedras. Este deslocamento acarretou consequências importantes para nossa historiografia. As ciências da linguagem no Brasil passaram, aos poucos, a serem vistas como uma atividade de grupos, mais do que de indivíduos isolados; de fato, o conhecimento se constrói coletivamente, dia a dia, com muitos erros, mas também com alguns acertos.

\section{REFERÊNCIAS}

ADUSP. O Livro Negro da USP. O controle ideológico na Universidade. 2. ed. São Paulo: Associação dos Docentes da Universidade de São Paulo, 1979.

Alfa. Documentos do I Seminário de Linguística, promovido pela FFCL de Marília, v. 11, p. 7-11, 1967.

ALTMAN, C. Filologia e Linguística brasileiras, mais uma vez. In: SANSONE, O. C. (org.). A Historiografia Linguística no Brasil (1993-2018). Memória, Estudos. São Paulo: Pontes. 2018. p. 43-64.

ALTMAN, C. Avaliação da importância da Reunião no Cenário Científico do País. Pedido de Auxílio para Organização do 51 Seminário do GEL. São Paulo: FAPESP, 2003 (documento inédito).

ALTMAN, C. (org.). Revista do GEL. Em Homenagem a Carlos Franchi (1930-2002). n. especial. São Paulo: Contexto, 2002a.

ALTMAN, C. Relatório técnico e científico apresentado à FAPESP, relativo à realização do $50^{\circ}$ Seminário do GEL. São Paulo: FAPESP, 2002b (documento inédito).

ALTMAN, C. Apresentação da equipe que constitui a Diretoria do GEL para o biênio 2001-2003. Marília: 49 Seminário do GEL, 24 de maio de 2001, documento inédito, 2001.

ALTMAN, C. Trinta anos de Linguística Brasileira: o caso do GEL. Conferência proferida por ocasião do $42^{\circ}$ seminário - 25 anos do GEL - Universidade de São Paulo, 21 de maio de 1994a. 
ALTMAN, C. A Pesquisa Linguística no Brasil. São Paulo: Humanitas, 1994b.

CASTILHO, A. T. de. Rumos da Dialetologia Portuguesa. Proferido no I Seminário de Pós-Graduação, promovido pela FFCL de Marília, em 1971. Alfa, v. 18/19, p. 115-153, 1972/1973

CASTILHO, A. T. de. A Reforma dos Cursos de Letras. Alfa, v. 3, n. 53, 1963.

DURHAM, E. R. A universidade brasileira e os impasses da transformação. Ciência e Cultura, v. 38, n .12, 2004-2018 [1986].

FIORIN, J. L. Curso de Letras: um balanço no $10^{\circ}$ aniversário da UNESP. Alfa, v. 30/31, p. 1-10, 1986/1987.

FRANÇA, A. M. R.; SANTOS, L. G. P. dos; COELHO, O. F.; OLIVEIRA, R. de C. C. de; LEITE, V. C. Mapeamento historiográfico da produção linguística nos 25 anos do GEL - Grupo de Estudos Linguísticos do Estado de São Paulo. Trabalho apresentado no $42^{\circ}$ seminário - 25 anos do GEL - Universidade de São Paulo, 21 de maio de 1994.

MURRAY, S. O. Theory groups and the study of language in North America. A social history. Amsterdam \& Philadelphia: John Benjamins. (Ed. revista de Group Formation in Social Science. USA/ Canada: Linguistic Research, Inc. Carbondale and Edmonton, 1983), 1994.

NARO, A. J. (org.). Tendências atuais da linguística e da filologia no Brasil. Tradução Maria Candida Diaz Bordenave e Marilda Winkler Averbug dos originais em inglês [1968]. Rio de Janeiro: Francisco Alves, 1976.

PRETI, D. Subsídios para a história do projeto NURC em São Paulo. In: CÂNDIDO, A. et al. Estudos de filologia e linguística: em homenagem a Isaac Nicolau Salum. São Paulo: T.A. Queiroz/Edusp. 1981.

PROTA, L. Um novo modelo de universidade. São Paulo: Convívio, 1987.

RODRIGUES, A. N. O dialeto caipira na região de Piracicaba. São Paulo: Ática, 1974.

SALUM, I. N. Filologia Românica e Pós-Graduação. Proferido no I Seminário de PósGraduação, promovido pela FFCL de Marília, em 1971. Alfa, v. 18/19, p. 483-487, 1972/1973. 